\title{
Book review: Across Atlantic Ice: The Origin of America's Clovis Culture
}

\author{
Mercedes Okumura
}

PPGArq, National Museum, Federal University of Rio de Janeiro, Quinta da Boa Vista, São Cristóvão, 20940040, Rio de Janeiro, RJ, Brazil. Email: mercedes@mn.ufrj.br

\section{Across Atlantic Ice: The Origin of America's Clovis Culture by Dennis J. Stanford and Bruce A. Bradley University of California Press, 2013, pp. 336. ISBN 9780520275782 http://www.ucpress.edu/book.php?isbn=9780520275782}

North American Clovis culture is one of the most popular and well known archaeological cultures (known even by many laymen), however, our knowledge as to its origins is still quite scarce. The idea of this book is to challenge the long standing model that the ancestors of the Clovis people originated from an Asian tradition that came out of north-eastern Asia at the end of the Last Glacial Maximum (LGM).

Published by the School of History, Classics and Archaeology, University of Edinburgh ISSN: 2055-0472. URL: http://journals.ed.ac.uk/lithicstudies/

This work is licensed under a Creative Commons Attribution 2.5 UK: Scotland License. 
The book is divided into two parts, the first (Palaeolithic Peoples) presents a review challenging the classical ideas about Clovis as the first American settlers, as well as data supporting the hypothesis that the groups who originated pre-Clovis and Clovis technology, cannot be found in Beringia. The second part (The Solutrean Hypothesis) is focused on presenting evidence to support the historical connection between the Solutrean and Clovis cultures.

The authors begin the book with a chapter dedicated to the basics of flaked stone technology, emphasizing the main topics related to the technological comparisons used to suggest historical relations. The reader is provided with useful information on different types of Palaeolithic traditions and manufacturing techniques.

The second chapter "Clovis: The First American Settlers?” presents an interesting review about what could characterize Clovis besides the lithic artefacts. Based on the number of diagnostic points and their variation, as well as the raw material source of cache artefacts, the authors propose a southeastern settlement direction for Clovis. In terms of subsistence, there is evidence that it varied according to the different environments that were exploited. The authors also describe artefacts made from organic materials (bone, antler, ivory tools), as well as small incised stones, which might be Clovis ornamentation.

According to the classic model, the ancestors of the Clovis culture arrived from Beringia. Therefore, the next chapter is devoted to disproving such a hypothesis. In fact, the data presented by the authors indicates that Beringia lacks thinned bifacial technology and large blades, which are the main characteristics of Clovis technology. Data on chronology also indicates that humans only colonized Beringia less than 12,000 years ago, when the Ice Age ended, and therefore the timing of the colonization also presents problems in supporting the classic model.

The fourth chapter, "Challenging the Clovis First Model", proposes that if Clovis was well established in America by at least 13,000 years ago, then its potential ancestor has to be sought in the earlier assemblages. Two Mid-Atlantic Early Paleo-American sites (Meadowcroft and Cactus Hill) presenting dates earlier than Clovis, as well as thinning and biface technology, are presented as potential ancestors. Other relevant sites (Miles Point, Oyster Cave, and Cinmar) are also described. Moreover, the technological differences between early Mid-Atlantic sites and Clovis are discussed, emphasizing the presence of basal fluting as a basal thinning technique present in Clovis points, but not in the Mid-Atlantic ones.

Due to the lack of evidence of sites in Beringia that would be suitable to be considered as pre-Clovis and Clovis ancestors (with respect to chronology and technology), in Chapter 5 the authors explore the Solutrean culture. There is a brief introduction to the European Upper Palaeolithic sequence, in order to emphasize the uniqueness of the Solutrean occupation. Solutrean sites are dated generally from 25,000 to 16,500 years before present, during the last major glacial period and sites in Southwestern France and Northern Spain are given a greater emphasis due to their higher degree of technological similarity with pre-Clovis and Clovis artefacts. All known Solutrean sites are located either in shelters or caves and their distribution is more restricted than the other Upper Palaeolithic cultures, although Solutrean subsistence behaviour seems to be similar to the general European pattern of a land-based hunting economy. In terms of flaked stone tools, the thinned bipointed bifaces (known as laurel leafs) are the most distinctive Solutrean artefact. Their small thickness-to-width ratio and their large size (some presenting more than $50 \mathrm{~cm}$ in length) suggest that they were made for symbolic purposes, embodying the skills of precision, timing and strategic planning, also needed for the successful accomplishment of complex hunting. Such laurel leafs are also found in caches. 
Chapters 6 and 7 are devoted to a quantitative and qualitative comparison between different groups (Clovis, European Upper Palaeolithic, and Beringian) using mainly technological choices, in order to establish reliable cultural connections. The quantitative comparison using cluster analysis by tool type and technology shows early Paleo-American assemblages to be close to Solutrean assemblages. Such a similarity was also observed in the qualitative comparison, which included artefact form and function, cultural innovation, subsistence patterns, environmental settings, and specific human behaviour such as art and biface caches, among others. Differences in artefact types among assemblages were also presented as contrary evidence for a Clovis-Solutrean connection.

The next chapter presents evidence on how and why a trans-Atlantic connection could have taken place. The authors describe how some Solutrean groups would have expanded their territorial economic resource base to include maritime resources. Most of the model is based on sites near the ice age coast in Northern Spain, especially La Rivera Cave.

Chapter 9 shows how the climate and the environment changed during the LGM. Evidence shows that North Atlantic waters were not too cold and their productivity was not too low to sustain animal life (including humans). The authors propose that some Solutrean groups would have adopted a maritime economy and, while exploring such resources, would have crossed the Atlantic. Such an idea is further developed in the next chapter, invoking a convergence of lifestyle strategies between Inuit and Solutrean groups, justified by the similar environmental challenges faced by both peoples. The authors suggest Solutrean peoples adapted to changes in polar front position by improving their skills to follow maritime animals (such as seals) across open water. In that way, some Solutrean groups would have moved along with the ice edge, eventually expanding their territory and incorporating the eastern shore of North America.

The authors conclude by saying that, based on dating, comparisons of archaeological assemblages, and paleo-environmental data, there is stronger evidence that the predecessors of the Clovis people were immigrants from southwestern Europe during the LGM in contrast to the traditional model where north-eastern Asian groups are Clovis ancestors.

The book is well written and it makes smooth and stimulating reading, having won the Smithsonian Secretary's Research Award in February 2016. For those interested in lithic studies, it shows how that area can play a major role in establishing historical connections between archaeological cultures when other important contextual information is also considered. 